\title{
GEOSPATIAL MODELLING APPROACH FOR INTERLINKING OF RIVERS: A CASE STUDY OF VAMSADHARA AND NAGAVALI RIVER SYSTEMS IN SRIKAKULAM, ANDHRA PRADESH
}

\author{
A. Swathi Lakshmi*, Sameer Saran, S.K. Srivastav, Y.V.N Krishna Murthy \\ Indian Institute of Remote Sensing, Dehradun \\ *(swathi.ayalasomayajula@gmail.com)
}

KEYWORDS: Geospatial Modelling, Majority Rule Based (MRB) aggregation, Analytical Hierarchy Process (AHP) based MultiCriteria Decision Making (MCDM), Network Routing, and Interlinking of Rivers.

\begin{abstract}
:
India is prone to several natural disasters such as floods, droughts, cyclones, landslides and earthquakes on account of its geoclimatic conditions. But the most frequent and prominent disasters are floods and droughts. So to reduce the impact of floods and droughts in India, interlinking of rivers is one of the best solutions to transfer the surplus flood waters to deficit/drought prone areas. Geospatial modelling provides a holistic approach to generate probable interlinking routes of rivers based on existing geoinformatics tools and technologies. In the present study, SRTM DEM and AWiFS datasets coupled with land-use/land -cover, geomorphology, soil and interpolated rainfall surface maps have been used to identify the potential routes in geospatial domain for interlinking of Vamsadhara and Nagavali River Systems in Srikakulam district, Andhra Pradesh. The first order derivatives are derived from DEM and road, railway and drainage networks have been delineated using the satellite data. The inundation map has been prepared using AWiFS derived Normalized Difference Water Index (NDWI). The Drought prone areas were delineated on the satellite image as per the records declared by Revenue Department, Srikakulam. Majority Rule Based (MRB) aggregation technique is performed to optimize the resolution of obtained data in order to retain the spatial variability of the classes. Analytical Hierarchy Process (AHP) based Multi-Criteria Decision Making (MCDM) is implemented to obtain the prioritization of parameters like geomorphology, soil, DEM, slope, and land use/land-cover. A likelihood grid has been generated and all the thematic layers are overlaid to identify the potential grids for routing optimization. To give a better routing map, impedance map has been generated and several other constraints are considered. The implementation of canal construction needs extra cost in some areas. The developed routing map is published into OGC WMS services using open source GeoServer and proposed routing service can be visualized over Bhuvan portal (http://www.bhuvan.nrsc.gov.in/). Thus the obtained routing map of proposed canals focuses on transferring the surplus waters to drought prone areas to solve the problem of water scarcity, to properly utilize the flood waters for irrigational purposes and also help in recharging of groundwater. Similar methodology can be adopted in other interlinking of river systems.
\end{abstract}

\section{INTRODUCTION}

India is blessed with abundant water resources in the form of lakes, rivers and ground water tables. Though many perennial rivers which serve the socio-economic purpose of people are present in India, it still leads to uneven distribution of river water due to diverse topographic and geological conditions(Rao et al. 2014). Within the $329 \mathrm{M}$ ha of geographical area, it experiences extremes of climate with mean annual rainfall varying from one part of the country to the other such as $100 \mathrm{~mm}$ in western Rajasthan to $11000 \mathrm{~mm}$ at cherrapunji in Meghalaya (Prakashvel, Dr. M. Krishnaveni, and Dr. M. Kaarmegam 2003)(Indian Water Resources Society, 1994). During the peak monsoon seasons, intolerable situations like - filling of the basins, discharge of surface/river waters into the oceans and drowning of agriculture and urban areas etc are observed causing natural hazards like floods.

Floods are a natural phenomenon and have become common scenario in India. Severe floods occur every year in one part or the other causing tremendous damage to agriculture, life and property. Flooding is mainly caused by over-spilling of river banks and severity increases where there are obstructions like roads, railway networks, urban areas etc(Khanna et al. 2007).This scenario is most commonly observed during the monsoon seasons throughout the country. Due to improper utilization of these waters, most of the water is depleting in to the seas and oceans. In other words, flood waters are simply going as a waste in to seas and oceans. So we should ensure that flood waters are properly managed and used in an effective way in order to solve the problem of water scarcity for the other time periods.

To control the floods and utilize the waters for irrigation and other purposes, Interlinking of rivers can be a substantial solution to end up the problem of water scarcity. The concept of interlinking the rivers is not new(Kelli Krueger, Frances Segovia, and Monique Toubia 2007). Many people have put forward the proposal of interlinking the Indian rivers for a better sustainable development of the country(McCornick 2014) (Bharat R. Sharma, and Upali A. Amarasinghe 2008). Traditional methods were proposed and implemented for interlinking of rivers which is both cost effective and time consuming. But in the recent years, geospatial technology, GIS and its tools play a vital role in providing accurate solutions for environmental issues(Shahabi et al. 2006). GIS coupled with hydrological models also plays a key role in obtaining accurate results for the desired objectives(Chowdary et al. 2012). GIS techniques like overlay analysis, decision support systems and object oriented models have been proposed for the interlinking of rivers. Of these techniques Multi Criteria Analysis has evolved to be an effective way of decision making because this technique considers various issues/decisions related to Hydrological, environmental, geomorphological, agricultural and socio-economical for producing a more suitable site map. Analytical Hierarchy Process (AHP) based Multi-Criteria Decision Making (MCDM) is a decision support tool which can be used to solve complex decision problems(Triantaphyllou and Mann 1995). 
Geospatial technologies provide a wide range of innovative and cost effective solutions for interlinking of rivers(Njike Chigbu and Daniel Onukaogu 2013). The advanced geoinformation technologies are extensively useful in integrating the large amounts of data from various sources like topographic maps, satellite images and Digital elevation Models (DEM) for an easier and accurate decision making(Sanyal and $\mathrm{Lu}$ 2004). In fact, it is only space technology, which has for the first time provided the basic information needed in the space, time and frequency domain (Khanna et al. 2007).

The main objective of this project is to interlink the rivers for proper utilization of the excess flood waters. To accomplish the main objective of the present study the following steps has to be carried out:

I. Normalize the input parameters (DEM, LULC, Rainfall etc) by performing multi-scale data integration using aggregation techniques.

II. Parameter prioritization using AHP based Multi Criteria Decision Making.

III. To generate the likelihood grids for each of the prioritized parameter.

IV. Final suitable site selection for interlinking of rivers using routing and aggregation techniques.

V. Publishing the routing map on to the web.

\section{STUDY AREA DESCRIPTION}

The study area consists of two important east flowing rivers Vamsadhara and Nagavali, covering the administrative district of Srikakulam in Andhra Pradesh, India. The study area is situated at the extreme north-eastern part of Andhra Pradesh with the coordinates ranging from $18^{\circ}-20^{\prime}$ and $19^{\circ}-10^{\prime} \mathrm{N}$ latitudes to $83^{\circ}-50^{\prime}$ and $84^{\circ}-50^{\prime} \mathrm{E}$ longitudes. It occupies an area of $5837 \mathrm{~km}^{2}$ and with a coastline of $193 \mathrm{~km}$. The topography of the study area is highly rising (above 250MSL) with the elevations varying from north to south. About onethird of the district is covered with hills. The northern part comprises a part of devagiri forests and wastelands while the southern part includes a major town srikakulam along with several villages. Some parts of the district are plain terrains with intense agriculture whereas other parts have rocky and hilly terrain covered with forests. Due to variation in topography, the region has a tropical climate. The maximum temperature of thirty seven degrees $\left(37^{\circ} \mathrm{C}\right)$ and a minimum temperature of twenty five degrees $\left(25^{\circ} \mathrm{C}\right)$ are experienced during summer season. The average rainfall of the district is $1162 \mathrm{~mm}$. The temperature falls during the post monsoon months of October and November. This region also experiences winter with a maximum temperature of twenty degrees $\left(20^{\circ} \mathrm{C}\right)$ and a minimum temperature of fourteen degrees $\left(14^{\circ} \mathrm{C}\right)$ (Eadara and Karanam 2013). As per 2010-2011 census, the forest area of srikakulam district is 68,641 hectares which constitutes $12 \%$ of the total geographic area(MSME - Development Institute). The forests in the study area are the South Indian Moist Deciduous which includes mixed forests, Sal forests, hilly savannahs and dry ever-green miscellaneous forests. Agricultural sector plays a vital role in the districts economy. Agriculture in this area is mostly dependent on rainfall. Moreover, monsoons and seasonal conditions also influence the agriculture production. It has both kharif and Rabi type of vegetation. Crops like Paddy, Jowar, Cotton, Red gram, Chillies, Sugarcane, Pulses, Groundnut, Sunflower, Maize and Sesame are grown in this district. Of the total geographic area, 841.66 square kilometres consists of wastelands. Various categories of wastelands like gullied, salt affected, degraded pastures/grazing lands, water logged and marshy lands, barren rocky areas, mining and industrial wastelands etc., are present in the study area (Wastelands Atlas of India).

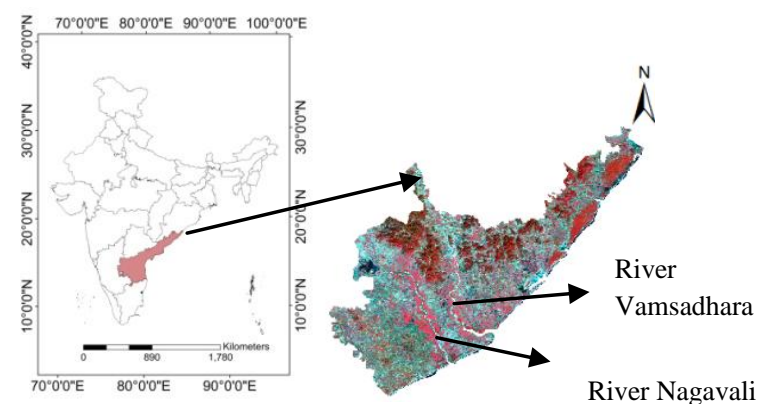

Fig 1: Study area- Srikakulam, Andhra Pradesh, India.

The study area is endowed with good rainfall and different types of soils like laterite and alluvial as it forms a part of stable peninsula. Besides the above soils it also contains other categories like sandy, loamy, clayey, clay skeletal and loamy skeletal. The Srikakulam district is geomorphologically characterized by rocks of Archean ages comprising of Granites and Charnockites, which have intruded into the highly folded and metamorphosed sedimentary rocks, represented by Khondalites series(Eadara and Karanam 2013).

\subsection{Data used}

Satellite images of IRS-P6 AWiFS sensor downloaded from Bhuvan website (http://bhuvan-noeda.nrsc.gov.in) for the period of pre and post monsoon seasons is used for the present study. Advanced Wide Field Sensor (AWiFS) camera is an improved version compared to the WiFS camera of IRS-1C/1D. It operates in four spectral bands, providing a spatial resolution of $56 \mathrm{~m}$ and covering a swath of $740 \mathrm{Km}$. The AWiFS camera is split into two separate electro-optic modules, AWiFS-A and AWiFS-B tilted by 11.94 degrees with respect to nadir. Shuttle Radar Topography Mission (SRTM) Digital Elevation Model of $90 \mathrm{~m}$ resolution, downloaded from United States Geological Survey (USGS) is used in the study. Land Use/Land Cover map of 1:250000 scale with various classes like urban areas, agriculture, wastelands, water bodies, forests etc are present in the study area. The Rainfall data used in this study is from Indian Meteorological Department (IMD) with a spatial resolution of $1 / 2$ degree. Sandy, loamy, clayey, clayey skeletal and loamy skeletal categories are observed in the soil map of 1:1 million scale taken from National Bureau of Soil Survey (NBSS).Geomorphology map of 1:2 million scale taken from Geological Survey of India (GSI) and different geomorphic features like low-lying flats/plains are present along the river course, low-lying flats/terraces are present along the coast, colluvial foot slopes are observed at the bottom of the hilly terrains, ridges/hills with intervening broad undulation, ridges/hills with or without valley are present in the northern regions.

\section{METHODOLOGY}

Satellite images of IRS-P6 AWiFS acquired for the periods of pre and post monsoon months is used for the study. AWiFS Satellite image with green and NIR bands are used to generate Normalized Difference Water Index which helps in identifying the inundated areas. The reason for using green and NIR bands is that these wavelengths will maximize the reflectance properties of water. Using the image alarm technique, the pixels 
in the View that belong to a particular class are selected according to the parallelepiped decision rule. Drainage and inundation map has been prepared using the satellite images.
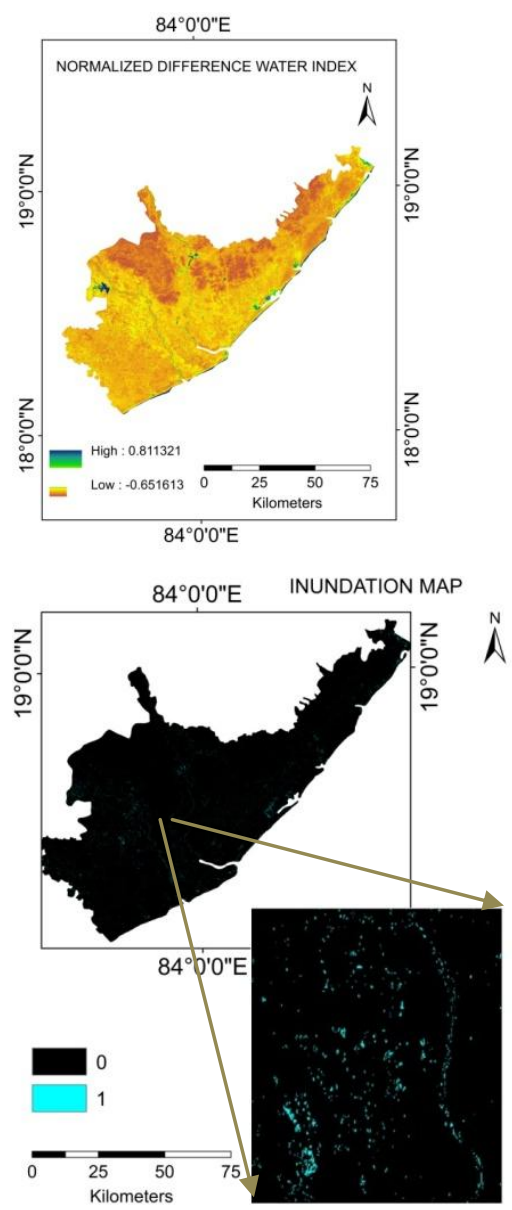

Fig 2: Maps representing NDWI and INUNDATION

The obtained DEM has voids and in order to fill those voids it has been corrected. Slope also called as gradient is an important terrain parameter and first order derivative which can be defined as "the rate of minimum change in z-value from each cell" is generated from the corrected DEM. Other derivatives such as Flow direction and Flow accumulation are also prepared using the DEM. Topographic Wetness Index map which is useful in hydrology, agriculture, geomorphology, and vegetation studies has been prepared using Slope and Flow accumulation map. This represents the spatial distribution of soil moisture, surface saturation, ground water recharge and discharge areas, as well as potential runoff generation. TWI values will vary by landscape and DEM, but they typically range from less than 1 (dry cells) to greater than 20 (wet cells).

To accomplish the main task of this study, it has been necessary to undergo certain Geoinformatics approaches. As the Land Use/Land Cover map, Geomorphology map, Soil map and Slope map are obtained at various scales and resolutions; Multi-Scale Integration using Majority Rule Based Aggregation technique has been applied to optimize the resolution of each thematic layer. The following figure represents each thematic layer after performing Multi-Scale Integration using Majority Rule Based Aggregation technique.
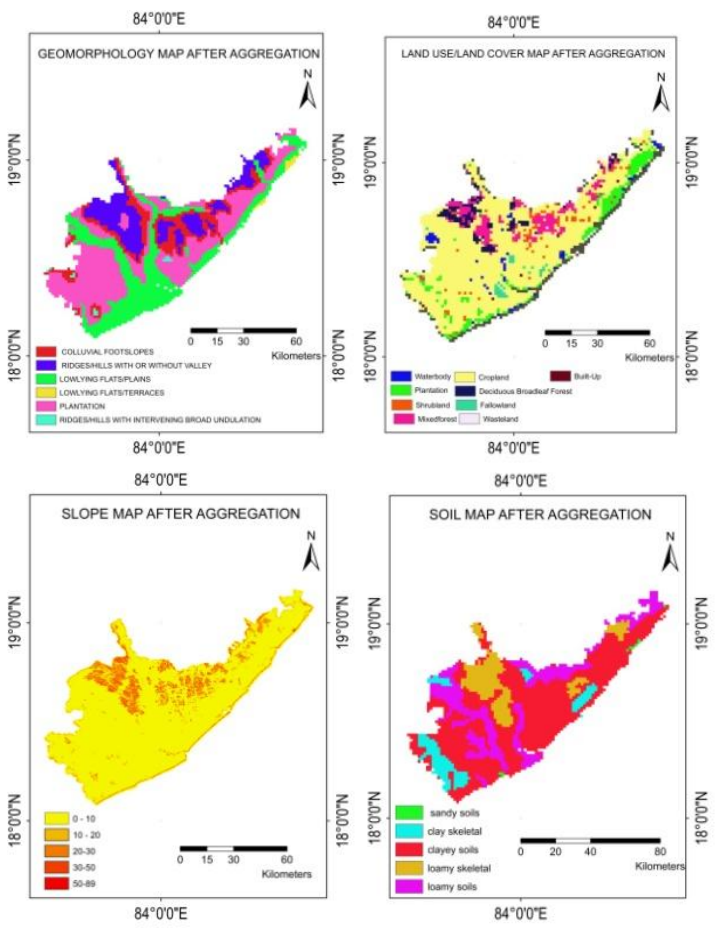

Fig 3: Thematic layers after performing Majority Rule Based Aggregation

Multi-Criteria Analysis, useful in solving real world problems is carried out to obtain the prioritization of parameters. Analytical Hierarchy Process based Multi-Criteria Decision Making method is applied to each thematic layer to obtain the priority vectors. AHP is developed by Thomas Saaty with three main principles: decomposition, comparative judgment and synthesis of priorities. Each thematic layer is decomposed in to various factors and certain weights are given to each factor based on the scale developed by Thomas Saaty. This developed matrix is the pair-wise judgment matrix and this is normalized to derive the relative weights for each factor. Consistency Analysis is carried out and Consistency Measure, Consistency Index, Consistency Ratio are calculated. Consistency Ratio of $<0.1$ is acceptable and it is maintained throughout. Ranking for each factor is given according to the Consistency Measure obtained. Highest Consistency Measure is given high rank and the Consistency Measure with least value is given least rank. Based on these ranks, each factor is divided into high, medium and low.

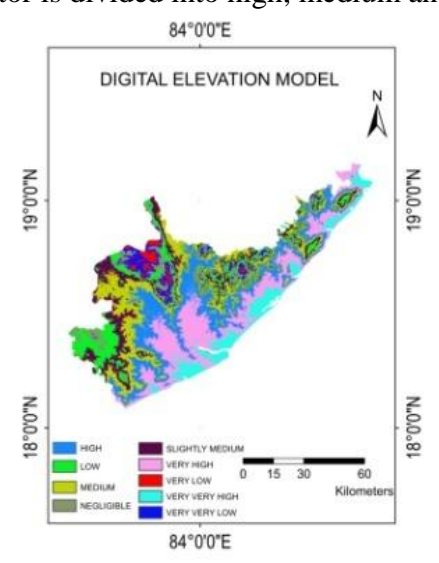




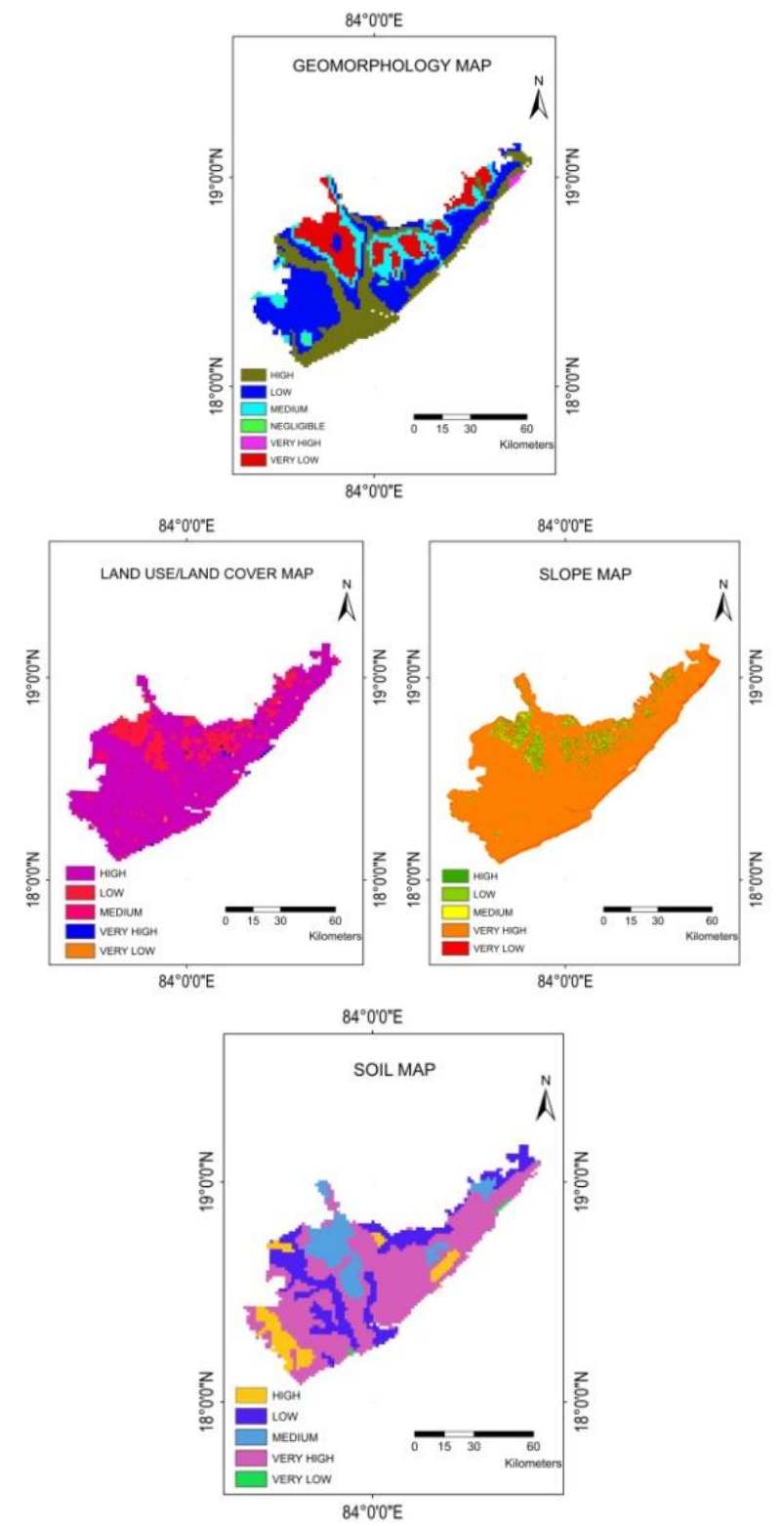

Fig 4: Thematic layers after performing Analytical Hierarchy Process based Multi-Criteria Decision Making

A mesh like structure is developed in Arcmap-10 using the Fishnet model. After performing Analytical Hierarchy Process based Multi-Criteria Decision Making, summation of all the thematic layers is done. Aggregated likelihood grids are generated and the obtained values are assigned to each individual grid. The obtained values vary from 2-29 which means High values are more potential whereas low values are least potential for routing. These values represent the impedances and a probable routing map has been developed from these impedances. Constraint map has been generated for the study area in order to avoid such areas. Probable routing is given to fulfill the main objective by considering the impedance map, constraint map, inundation map and rainfall statistics. Even though many routes are obtained, the shortest possible routes are identified in order to fulfill the objective of the study as the ultimate goal of the study is to divert waters in a shortest path. Three canals are proposed for the entire study. One canal which is $16 \mathrm{~km}$ long -interlink the two rivers, second one transfer the flood waters from River Vamsadhara to drought areas. Finally the third canal will transfer the flood waters of River Nagavali to agricultural fields by self-linking. Cost constraint is involved as it is necessary to dig a tunnel in passing a canal through higher elevations.

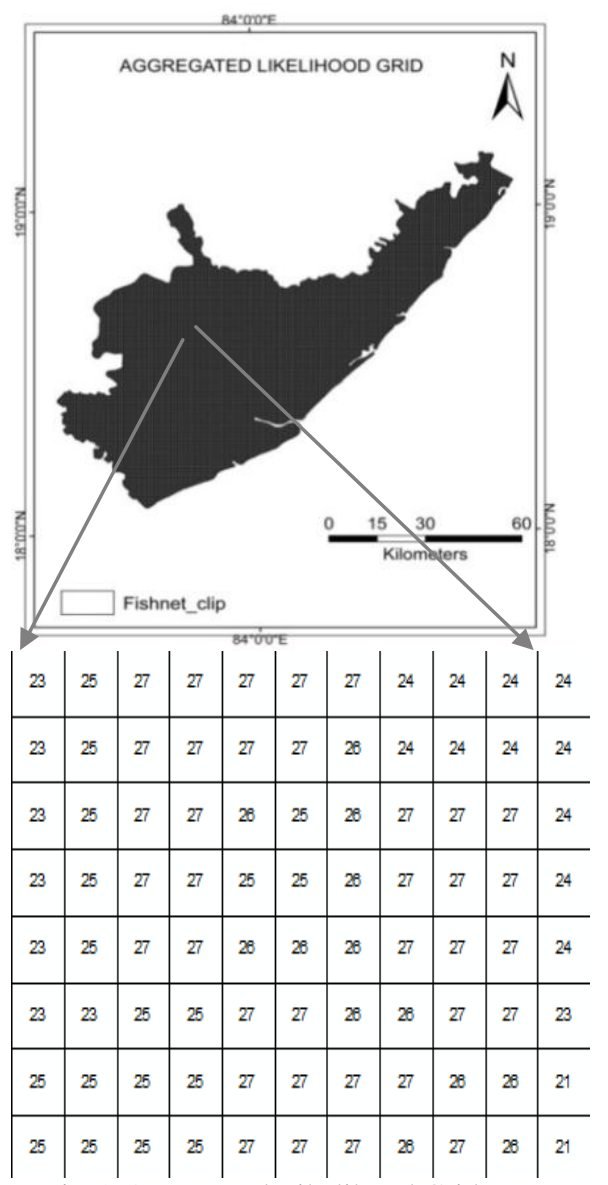

Fig 5: Aggregated Likelihood Grids

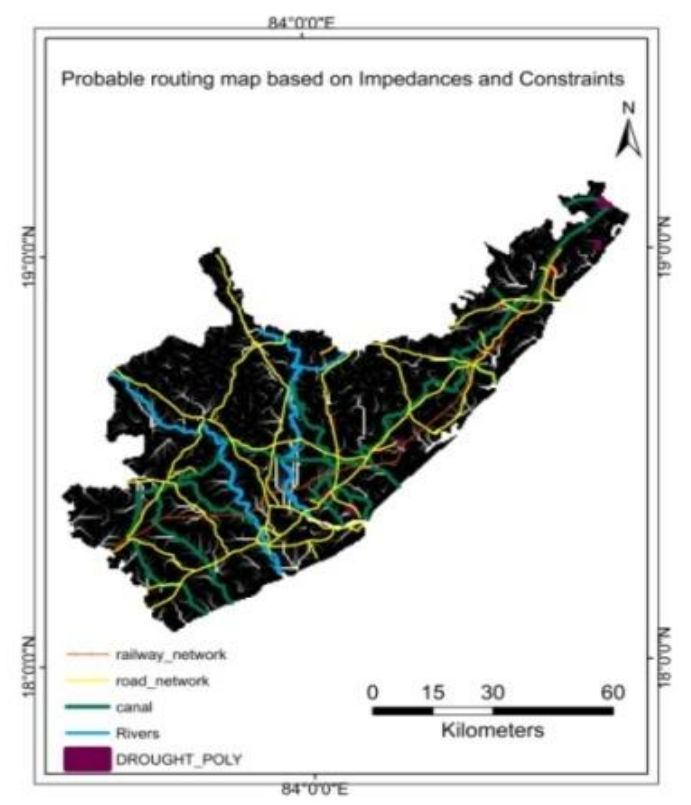

Fig 6a: Representing Probable routing map based on Impedances and Constraints 


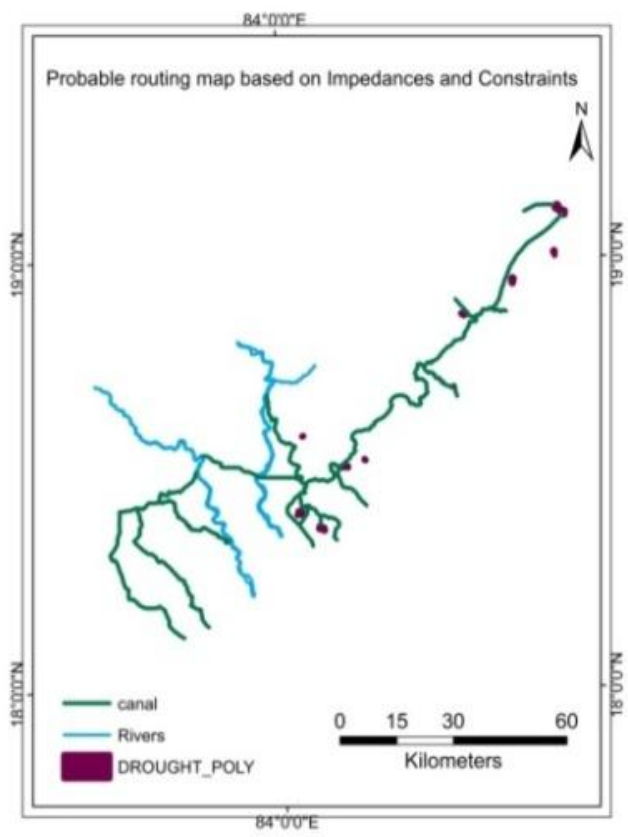

Fig 6b: Representing Probable routing map based on Impedances and Constraints

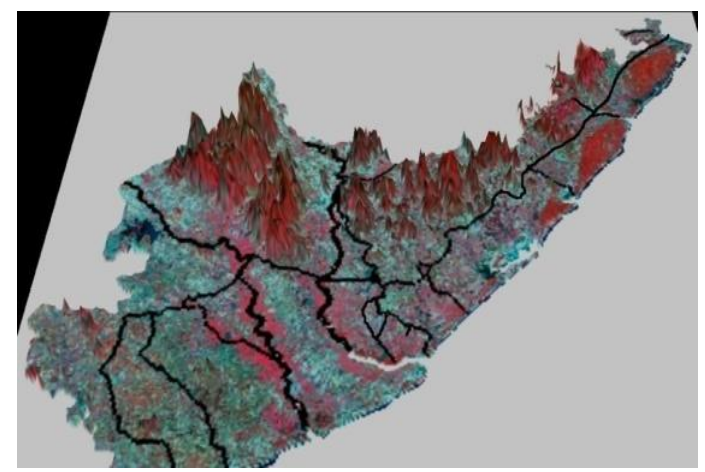

Fig 7: Perspective View of the obtained Routing map

As it is important to take the decisions of every individual in diverting the natural resources like water, the developed routing map has been published on to the GeoServer using open source tools like Postgis-Postgresql. The obtained routing map is also published on to the Bhuvan portal using WMS services with a Keyhole Mark-up Language (KML) file generated from the GeoServer.

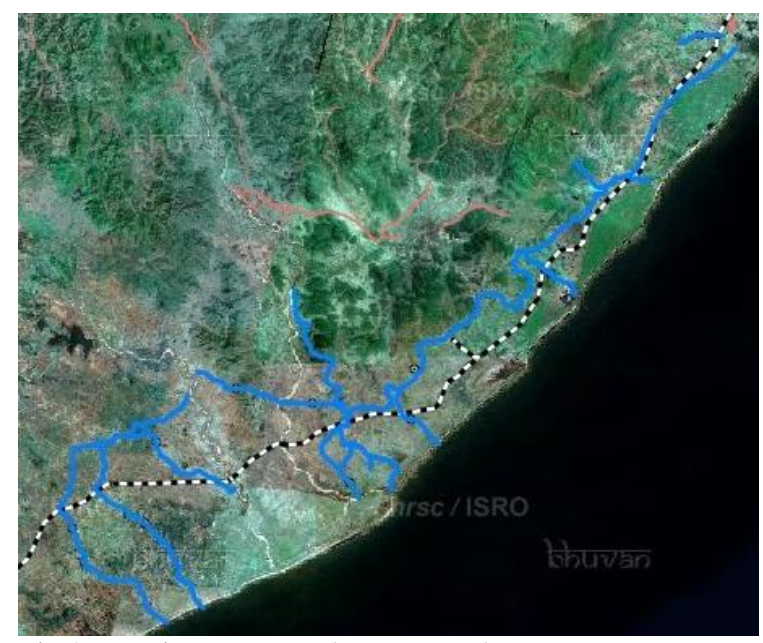

Fig 8: Routing map on Bhuvan Portal

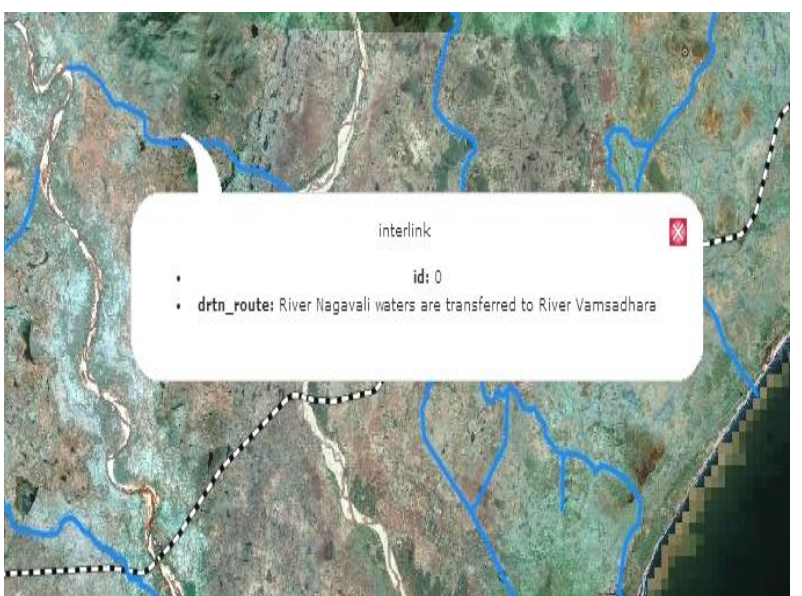

Fig 9: Routing map on Bhuvan Portal with Routes

\section{RESULTS AND DISCUSSIONS}

The main purpose of this project is to interlink the rivers so that flood waters can be transferred to drought areas and agricultural fields. To accomplish the main objective of the study, it has been necessary to undergo certain process like aggregation and Multi-Criteria Decision Making. It is a challenging task as it involves various parameters like Land Use/Land Cover, Geomorphology, Soil, Digital Elevation Model, slope etc. Majority Rule Based Aggregation technique is performed in order to optimize the resolution as all the thematic layers are obtained at various scales. MRB as the term suggests, it only considers majority of the class labels present in each thematic layer. While performing aggregation it is observed that there is randomness like loss of spatial pattern and detail. It is also observed that by using the MRB technique, dominant classes are chosen leaving behind the least dominant classes. Normalized Difference Water Index map generated using the green and NIR bands will maximize the reflectance properties of water bodies. With the help of NDWI, inundated areas for the study are identified and the inundation map for the corresponding study area has been prepared. The zero and negative values of NDWI represent soil, terrestrial vegetation whereas positive values represent water bodies. Various maps are generated like flow direction, flow accumulation, Topographic Wetness Index (TWI) from DEM.

Now-a-days, GIS and spatial decision modeling are the new techniques implemented to solve the real world problems. In the present study, AHP based MCDM techniques are used to solve the multi-criteria decision problems. Weightage for each factor is given considering the flood condition. The high permeable areas are given low weight and the low permeable areas are given more weight. Little Inconsistency is obtained in achieving the priority vectors using the AHP based MCDM technique. Multi-Criteria technique was very much helpful in evaluating more number of factors and a good accuracy is maintained throughout. MCDM plays a major role as it considers the weights given by experts than taking itself. Multi-Criteria Decision Making on each thematic layer is performed; summation of all the layers is done to obtain a unique value.

It is important to develop a spatial decision model with the potential zones to provide a better routing considering various issues related to interlinking of rivers. Besides the environmental parameters, socio-economic parameters are also considered to be important to give a better routing. So, a mesh with each individual grid of $500 \mathrm{mX} 500 \mathrm{~m}$ is considered to be 
nominal for the entire study area, as the thematic layers are at various scales. Each individual grid is now assigned with a value- high values representing high possibility and low values represent the least possibility for routing. The routing for the study is given based on the values generated for each grid. The direction for routing is followed from high value to low value. Constraints like roads, railways and settlements are considered. Rainfall map for the corresponding study has been used to identify the high and low rainfall areas. In some regions there are dense forests when a perfect routing is not obtained. In order to construct a canal factors like slope and elevation plays a major role. When it comes to geomorphology perspective there are ridges so the cost constraint is involved in order to make a tunnel. Considering all these parameters and constraints a routing map is generated.

Even though many routes are obtained for routing, the most possible routes are selected, as our motto is to interlink the rivers in a shortest path. Constructing canal in hilly terrains and forest areas is avoided as it involves huge expenditures and damage. Lakes in this area are utilized and also the existing dry channels are utilized to transfer the flood waters to agriculture fields and drought areas. However, Interlinking of rivers is a challenging task in rugged terrains and it is also has limitations when working with constraints like railways, roads, settlements, forests and also with some geomorphologic features.

\section{CONCLUSIONS}

It is indeed important to consider the decision of every individual in distributing the waters resources. So, the obtained routing map from developed spatial decision model is published on to the GeoServer and the same is added on to the Bhuvan portal using the generated KML file. This developed model can provide lots of information to various categories of people eg. farmers, water managers, engineers, administrators. The entire project can be browsed by all the people and they can get certain benefits out of it. The cost for publishing the developed routing map on to the GeoServer is completely free as it is open source software. Open source software's are becoming more popular now-a-days as they are secure and the person operating them has more control over it.

The work presented can be further improved by considering the following:

- Use of high resolution data can be of great advantage in obtaining the accurate results in the case of land use/land cover, geomorphology, soil etc.

- Use of microwave data will be constructive in delineating the flood areas.

- $\quad$ Though transferring the flood waters by constructing canals is implemented in this study, the flood waters can also be stored in harvesting pits by which the wastelands in the particular study area can be utilized.

\section{REFERENCES}

Bharat R. Sharma,, and Upali A. Amarasinghe. 2008. Strategic Analyses of the National River Linking Project (NRLP) of India. Colombo: International Water Management Institute.
Chowdary, V. M., V. R. Desai, Mukesh Gupta, A. Jeyaram, and YVNK Murthy. 2012. "Runoff Simulation Using Distributed Hydrological Modeling Approach, Remote Sensing and GIS Techniques: A Case Study from an Indian Agricultural Watershed." ISPRS-International Archives of the Photogrammetry, Remote Sensing and Spatial Information Sciences 1: 203-7.

Eadara, Amminedu, and Harikrishna Karanam. 2013. "Slope Studies of Vamsadhara River Basin: A Quantitative Approach.” Variations 3 (1).

Kelli Krueger, Frances Segovia, and Monique Toubia. 2007. Assessment of the India River linking plan: A closer look at the Ken-Betwa pilot link. University of Michigan.

Khanna, R. K., C. K. Agrawal, Pravin Kumar, and Chief Engineer Director. 2007. "Remote Sensing and GIS Applications In Flood Management." Central Water Commission, 2-10.

M S ME - De v e 1 o pm e nt I ns t it ut e. Brief Industrial Profile of Srikakulam District. Visakhapatnam.

McCornick, Peter. 2014. "India's River Linking Project: The State of the Debate1 Tushaar Shah Upali Amrasinghe" Draft. Accessed November 11.

Njike Chigbu, and Daniel Onukaogu 2013. "Role of Geospatial Technology in Environmental Sustainability in Nigeria-An Overview", May.

Prakashvel, J., Dr. M. Krishnaveni, and Dr. M. Kaarmegam. 2003. "GIS and Visualisation Capabilities for Interlinking of Indian Rivers." Map Asia Conference.

Rao, N. Bhaskara, N. Srinivas, BS Prakasa Rao, G. Jai Sankar, V. Venkateswara Rao, E. Amminedu, N. Venkateswarlu, N. Rajesh, P. Kesava Rao, and M. Satya Kumar. 2014. "Study on Nagarjunasagar to Somasila Link Canal Alignment and Its Impact on Environment Using IRS-P6, AWiFS Data.” J. Ind. Geophys. Union (April 2011) 15 (2): 113-24.

Sanyal, Joy, and X. X. Lu. 2004. "Application of Remote Sensing in Flood Management with Special Reference to Monsoon Asia: A Review." Natural Hazards 33 (2): 283-301.

Shahabi, Cyrus, Yao-Yi Chiang, Kelvin Chung, KaiChen Huang, Jeff Khoshgozaran-Haghighi, Craig Knoblock, Sung Chun Lee, Ulrich Neumann, Ram Nevatia, and Arjun Rihan. 2006. "Geodec: Enabling Geospatial Decision Making." In Multimedia and Expo, 2006 IEEE International Conference, 93-96. IEEE.

Triantaphyllou, Evangelos, and Stuart H. Mann. 1995. "Using the Analytic Hierarchy Process for Decision Making in Engineering Applications: Some Challenges." International Journal of Industrial Engineering: Applications and Practice 2 (1): 35-44. 